\title{
Cardiovascular Disease, Hypogonadism and Erectile Dysfunction: Early Detection, Prevention and the Positive Effects of Long-Term Testosterone
} Treatment: Prospective Observational, Real-Life Data

\author{
Mustafa Alwani (iD) 1,2 \\ Aksam Yassin (1D) ${ }^{2-4}$ \\ Raidh Talib ${ }^{2}$ \\ Ahmad Al-Qudimat (iD ${ }^{2}$ \\ Omar Aboumarzouk ${ }^{2}$ \\ Raed M Al-Zoubi ${ }^{2,5}$ \\ Farid Saad (iD ${ }^{6}$ \\ Karim S Haider ${ }^{7}$ \\ Abdulla Al Ansari ${ }^{2}$ \\ Jordan University of Science and \\ Technology, School of Medicine, Irbid, \\ Jordan; ${ }^{2}$ Hamad Medical Corporation, \\ Department of Surgery, Division of \\ Urology/Andrology and Section of \\ Surgical Research, Doha, Qatar; ${ }^{3}$ Weill \\ Cornell Medical College, New York, NY, \\ USA; ${ }^{4}$ Weill Cornell Medical College, \\ Doha, Qatar; ${ }^{5}$ Jordan University of \\ Science and Technology, Department of \\ Chemistry, Irbid, Jordan; ${ }^{6}$ Dresden \\ International University, Center of \\ Medicine and Health Sciences, Dresden, \\ Germany; ${ }^{7}$ Klinikum Bremen-Mitte, \\ Department of Urology, Bremen, \\ Germany
}

\begin{abstract}
Purpose: Erectile dysfunction (ED) is associated with testosterone deficiency and is a symptom of functional hypogonadism. A correlation between ED and cardiovascular disease (CVD) has been recognized, and ED has been proposed as an early marker of CVD. However, the relationship between ED and CVD risk in hypogonadism requires clarification and whether testosterone therapy (TTh) can be a beneficial treatment strategy, but long-term data are limited. This study investigates long-term TTh in men with hypogonadism and ED with a history of CVD.
\end{abstract}

Methods: Seventy-seven patients with a history of CVD and diagnosed with functional hypogonadism and erectile dysfunction (erectile function domain score $<21$ on the International Index of Erectile Function questionnaire (IIEF questions 1-5)) were enrolled and TTh effects on anthropometric and metabolic parameters investigated for a maximum duration of 12 years. All men received long-acting injections of testosterone undecanoate at 3-monthly intervals. Eight-year data were analysed. Data collection registry started in November 2004 till January 2015.

Results: In hypogonadal men receiving TTh, IIEF increased by 5.4 ( $\mathrm{p}<0.001$ ). Total weight loss was $23.6 \pm 0.6 \mathrm{~kg}$ after 8 years. HbAlc had declined by an average of $2.0 \%(\mathrm{P}<0.0001)$. Total cholesterol levels significantly declined following TTh after only 1 year $(\mathrm{P}<0.0001)$, and HDL increased from $1.6 \pm 0.5$ at baseline to $2 \pm 0.5 \mathrm{mmol} / \mathrm{L}$ following 8 years of TTh $(\mathrm{P}<0.0001)$. SBP decreased from $164 \pm 14$ at baseline to $133 \pm 9 \mathrm{mmHg}$, signifying a reduction of $33 \pm 1 \mathrm{mmHg}$ $(\mathrm{P}<0.0001)$.

Conclusion: In hypogonadal men with a history of CVD, TTh improves and preserves erectile function over prolonged periods with concurrent sustained improvements in cardiometabolic risk factors. Measuring ED and testosterone status may serve as an important male health indicator predicting subsequent CVD-related events and mortality and TTh may be an effective add-on treatment in secondary prevention of cardiovascular events in hypogonadal men with a history of CVD.

Keywords: functional hypogonadism, testosterone therapy, erectile function, cardiovascular disease

\section{Introduction}

Functional hypogonadism is a common medical condition affecting men, characterized by serum testosterone levels of $12.1 \mathrm{nmol} / \mathrm{L}(<350 \mathrm{ng} / \mathrm{dL})$ and at least one clinical symptom including sexual dysfunction (difficulty achieving organism,
Correspondence: Aksam Yassin Rathausallee 94 A, NorderstedtHamburg, 22846, Germany Tel +494052621 57 Fax +49405262820

Email yassin@t-online.de 
decrease in libido, erectile dysfunction, reduced physiologic erections, absent penile sensation, and decreased ejaculate), reduced stamina, changes in cholesterol levels, irritability, depressed mood, difficulty concentrating, anemia, osteoporosis, and hot flushes. ${ }^{1,2}$ Ageing males experience a progressive decline in serum testosterone levels leading to increased prevalence of testosterone deficiency and/or hypogonadism. ${ }^{3}$ Testosterone deficiency is highly prevalent in men with metabolic syndrome (MetS), type 2 diabetes (T2D) and established cardiovascular disease CVD, which also increases with age. ${ }^{3}$ A negative correlation between testosterone and cardiovascular outcomes has been established in epidemiological studies. ${ }^{4}$ While these associations do not imply causality, the ablation of testosterone through androgen deprivation therapy (ADT) for the treatment of prostate cancer increases the risk of cardiovascular events, including myocardial infarction (MI), stroke and overall cardiovascular mortality ${ }^{5}$ while increasing ED. ${ }^{6}$

ED is considered a vascular impairment that shares many risk factors with CVD, and has been proposed as an early marker of symptomatic CVD. ${ }^{7}$ T2D is a CVD risk factor and severity of ED in men with diabetes correlates with glycaemic control and disease duration. ${ }^{8}$ Additionally, there is a positive correlation between ED and silent $\mathrm{CAD}$ in men with seemingly well-controlled T2D. ${ }^{9}$ This has led to the suggestion that ED may be an early indicator of CVD. ${ }^{7,10,11}$ Reports have identified ED preceding $\mathrm{CAD}$ in about two-thirds of cases, with the time interval from ED to CAD symptoms being 2-3 years and a cardiovascular event 3-5 years. ${ }^{12,13}$ Furthermore, the severity of ED correlates with the severity of the CAD. ${ }^{14}$ Therefore, with ED commonly preceding CVD, its diagnosis may offer an opportunistic window for CVD risk mitigation and treating risk factors for ED may improve cardiovascular health.

Importantly, low testosterone levels are considered a predisposing risk for ED and both ED and testosterone deficiency are independently correlated with increased risk of CAD. ${ }^{16}$ Low testosterone increases the risk of men with erectile dysfunction dying from cardiovascular events. ${ }^{17}$ Furthermore, hypertension, hyperlipidaemia, diabetes, obesity, and depression are common conditions and risk factors for CVD that are also independently associated with ED and low testosterone. ${ }^{18}$ Testosterone therapy (TTh), the primary treatment for alleviating symptoms of functional hypogonadism, improves vascular dysfunction, reduces inflammation associated with atherosclerosis and improves clinical surrogate markers of atherosclerosis in hypogonadal men. ${ }^{19-21}$ Several RCTs have also demonstrated improvements in CVD risk factors following TTh, including insulin resistance, dyslipidemia, central adiposity and glycaemic control in hypogonadal men with T2D and/or $\mathrm{MetS}^{22-25}$; and, despite the complex relationship between testosterone and the cardiovascular system, TTh is considered safe once other comorbidities are addressed. ${ }^{26}$ Similarly, a number of studies have detailed the benefits and improvement of erectile function in hypogonadal men with ED following TTh. ${ }^{27-29}$ Furthermore, our previous study showed that long-term TTh for up to 12 years improved erectile function, anthropometric and cardiometabolic risk factors with the benefits of TTh being more pronounced in patients with moderate/severe $\mathrm{ED}$ at baseline than in patients with no/mild $\mathrm{ED}$ at baseline. $^{30}$

The role of low testosterone and ED as indicators of CVD still, however, remains unclear as long-term data are lacking. Whether treating functional hypogonadism with long-term TTh improves ED as an indicator of vascular health and subsequently improves CVD risk is not known. Testosterone administration is, however, indicated in the treatment of ED in hypogonadal males ${ }^{30}$ and such interventional studies afford an opportunity to investigate the potential therapeutic benefits of TTh on ED and CVD (including cardiovascular risk factors such as MetS and T2D). The aim of this study is to investigate the long-term effectiveness of TTh on improving erectile function as an indicator of cardiometabolic/vascular health in men with functional hypogonadism and a history of CVD, and demonstrating our results as a continuation work of previously published paper, ${ }^{29,56}$ in which long TTh treatment may decrease the risk of CVD by improving the cardiometabolic parameters in hypogonadal men.

\section{Patients and Methods}

\section{Patients}

This study represents two prospective, cumulative observational registry studies of 622 hypogonadal men presenting to two urological centers at the Institute of Urology and Andrology, Segeberger Kliniken, Norderstedt-Hamburg, Germany, and Men's Health Department, Hamad Medical Corporation, Doha, Qatar. Study participants were diagnosed with functional hypogonadism by fulfilling the criteria of having total testosterone $<12.1 \mathrm{nmol} / \mathrm{L}$ (mean $9.78 \pm 1.56$ $\mathrm{nmol} / \mathrm{L}$ ) in the presence of hypogonadal symptoms 
measured by the Aging Males' Symptoms scale (AMS)) and presenting with ED, having an IIEF-EF of $<21$ (maximum score: 30). Seventy-seven men with a history of CVD $(12.4 \%$ of the whole patient cohort), indicated by a previous diagnosis of coronary artery disease (CAD) $(n=48)$ and/or myocardial infarction (MI) $(n=40)$ and/or stroke $(n=7)$, were identified and included in the analysis. Forty-one patients (53\%) had T2D (Figure 1). Additionally, 72 patients (94\%) were on anti-hypertensives, 58 (75\%) on statins, and 37 (48\%) on antidiabetic medications. Patients received continuous testosterone undecanoate (TU) injections (Nebido ${ }^{\circledR}$; Bayer AG, Leverkusen, Germany) in 3-monthly intervals, following an initial interval of 6 weeks, for up to 8 years. Mean age at baseline of the 77 patients with a history of CVD was $60.65 \pm 4.98$ years and mean follow-up time was $7.29 \pm 1.20$ years. Exclusion criteria for TU administration included previous treatment with androgens, prostate cancer, breast cancer, recent angina, or severe untreated sleep apnea. Data collection registry started in November 2004 till January 2015. Ethical considerations were conducted in accordance with declaration of Helsinki, Institutional Review Board (IRB) approval were given from the ethics committee in the German medical association (Ärztekammer) (EK/CH/AU/ $1 / 6 / 2015$ ) for observational studies in patients receiving standard treatment were followed. After receiving an explanation regarding the nature and the purpose of the study, all subjects provided written consent to be included in the registry and have their data analyzed.

\section{Assessment and Follow-Up}

Assessments and measurements were taken at each or every second urology visit (between two and four times per year) and the annual average was calculated for each parameter. Erectile function was evaluated by the erectile function domain of the International Index of Erectile Function (IIEF-EF). ${ }^{31}$ IIEF is a validated, multidimensional, 15-item self-administered questionnaire commonly employed to assess erectile function and therapeutic efficacy thereof. ${ }^{32}$ Erectile function is specifically addressed by six questions from the "erectile function domain" of the questionnaire. Patients' height and weight were recorded and body mass index (BMI) was calculated $\left(\mathrm{BMI}=\right.$ weight $(\mathrm{kg}) /$ height $^{2}$ $\left(\mathrm{m}^{2}\right)$ ). Waist circumference (WC) was measured midway between the iliac crest and the costal margin. Systolic blood pressure (SBP), diastolic blood pressure (DPB) and pulse pressure (SBP-DPB) were also measured. Laboratory tests included glycated hemoglobin $\left(\mathrm{HbA}_{1 \mathrm{c}}\right)$ measured by high performance liquid chromatography (HPLC), and serum lipid profile including total cholesterol (TC), low-density lipoprotein cholesterol (LDL-C), high-density lipoprotein cholesterol (HDL-C), triglycerides (TGs) and non-HDL-C measured enzymatically with Alinity c-Module (Abbott).

\section{Statistical Analysis}

Statistical values were reported at each time point such as mean, median, standard deviation (SD), range, and sample size. Linear mixed-effects model was used in change of the outcome scores across the study period. To indicate follow-up

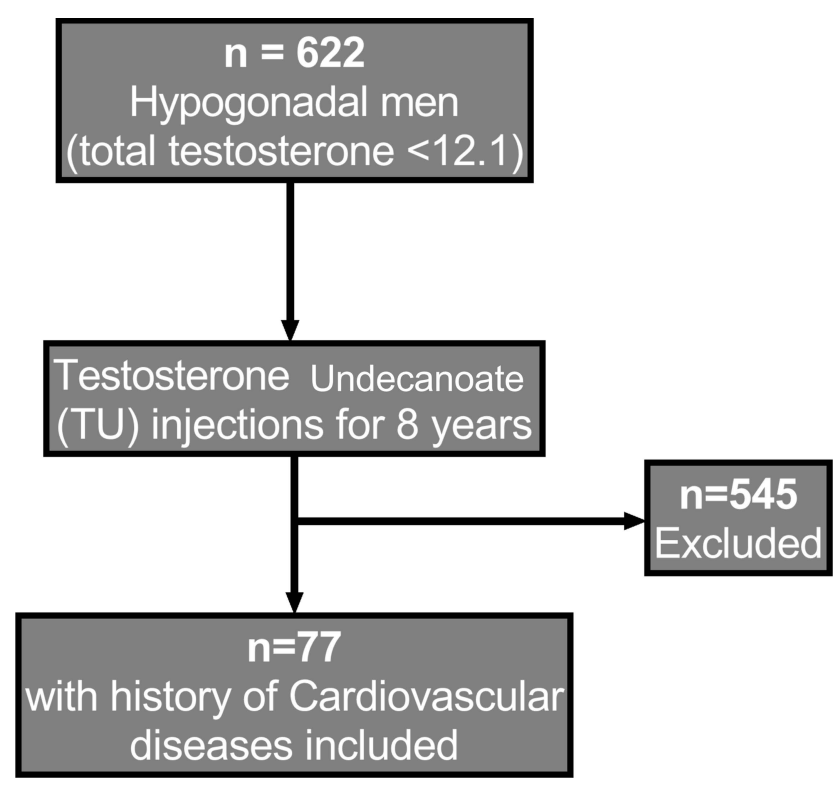

Figure I Flow chart for patient's selection. 
sessions, time was included as a fixed effect in the model. For the intercept, a random effect was included in the model. Computing the differences in least square means at baseline versus the score at each follow-up visit was used to determine the estimation and test of change in scores.

\section{Results}

\section{Effects of Long-Term TTh on Erectile} Function

Over the course of TTh, a significant and sustained improvement in erectile function domain score occurred: 19.6 \pm 6.34 at baseline, $21.4 \pm 5.36$ after 1 year, $22.8 \pm 4.97$ after 2 years, $23.8 \pm 4.52$ after 3 years, $24.3 \pm 4.34$ after 4 years, $24.4 \pm 4.53$ after 5 years, $24.4 \pm 4.57$ after 6 years, $24.2 \pm 4.76$ after 7 years and $24.5 \pm 4.4$ after 8 years (Figure 2). By the end of the follow-up period, the erectile function domain score had improved by $5.4(\mathrm{P}<0.0001)$ after model adjustment.

\section{Effects of Long-Term TTh on Weight Loss, WC, and BMI}

Weight declined progressively from year to year, reducing from $114.5 \pm 13.41$ to $90.42 \pm 8.77$ after 8 years of continuous
TTh in 77 hypogonadal men (Figure 3A) $(\mathrm{P}<0.0001)$ and significant weight loss (WL) totalled $23.6 \pm 0.6 \mathrm{~kg}(19.62 \pm$ $5.71 \%$ ) after 8 years. The percentage of change in weight was progressive and increased with continuous treatment (model adjusted $2.6 \%$ after 1 year, $7.1 \%$ after 2 years, $10.4 \%$ after 3 years, $13.2 \%$ after 4 years, $15.4 \%$ after 5 years, $17.4 \%$ after 6 years, $19.0 \%$ after 7 years, and $20.2 \%$ after 8 years) (Figure 3B). WL was complemented by a significant gradual decrease in $\mathrm{WC}$. WC reduction in response to $\mathrm{TTh}$ was significant from year to year decreasing from $111.8 \pm 8.2$ at baseline to $99.2 \pm 6.5 \mathrm{~cm}$ after 8 years of TTh (Figure 3C). WC reduction totalled to $12.5 \pm 0.4 \mathrm{~cm}$ at the end of the 8 -year follow-up period (model adjusted $1.7 \%$ after 1 year, $4.4 \%$ after 2 years, $6.3 \%$ after 3 years, 7.7\% after 4 years, $8.8 \%$ after 5 years, $9.6 \%$ after 6 years, $10.4 \%$ after 7 years, and $11.1 \%$ after 8 years). BMI also reduced considerably over the entire followup period with a mean reduction of $8 \mathrm{~kg} / \mathrm{m}^{2}$ (Figure 3D).

\section{Effects of Long-Term TTh on CVD Risk Factors \\ Effects on $\mathrm{HbA} \mathrm{A}_{\mathrm{Ic}}$}

$\mathrm{HbA}_{1 \mathrm{c}}$ levels were significantly reduced year to year following TTh: $7.6 \%$ at baseline, $7.2 \%$ after 1 year, $6.8 \%$

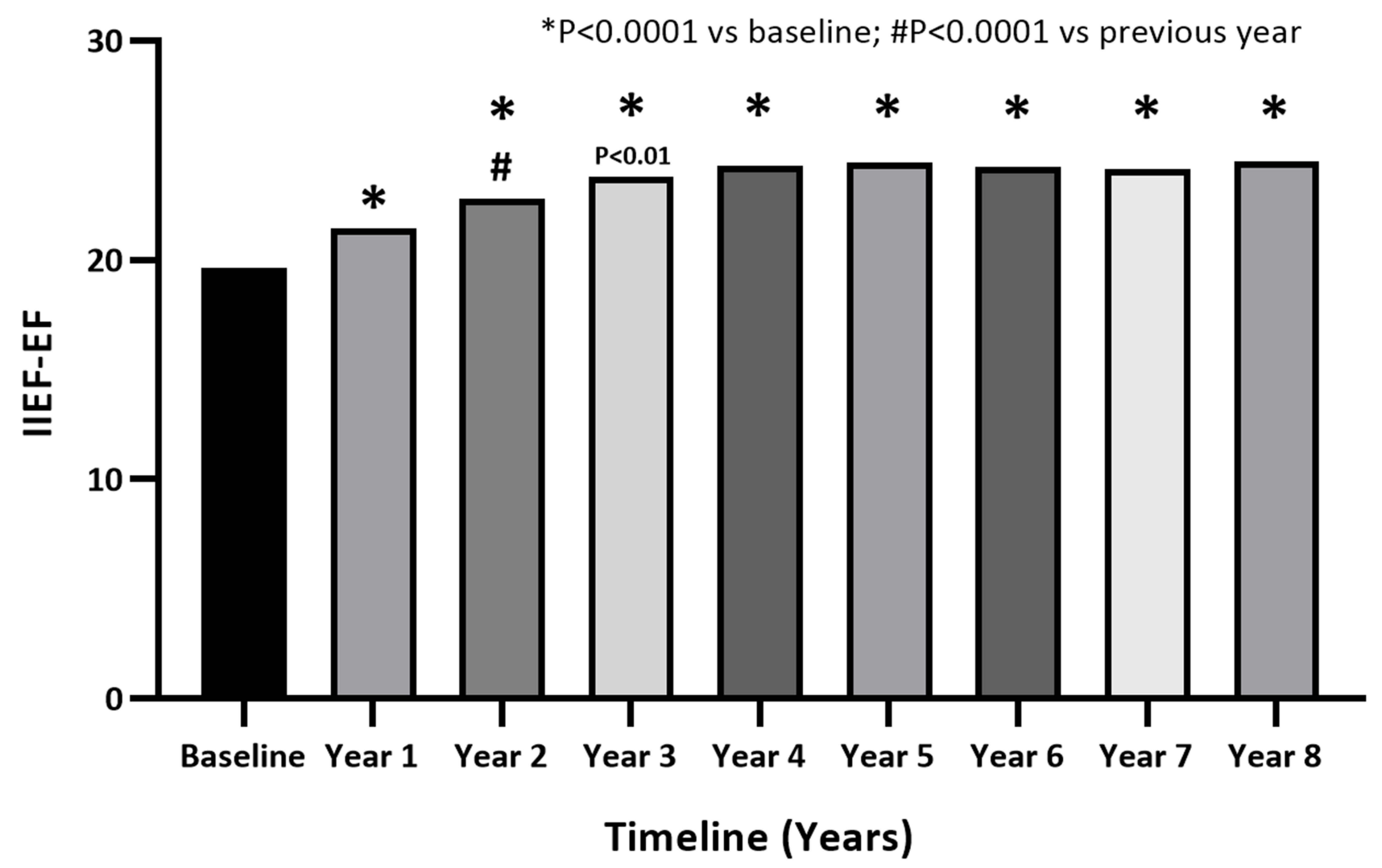

Figure 2 International index of erectile function - erectile function domain (IIEF-EF) in 77 hypogonadal men with a CVD history receiving continuous treatment with testosterone undecanoate. Data are shown as mean. ${ }^{*} p<0.0001$ vs baseline. $\# p<0.0001$ vs previous year. 
A

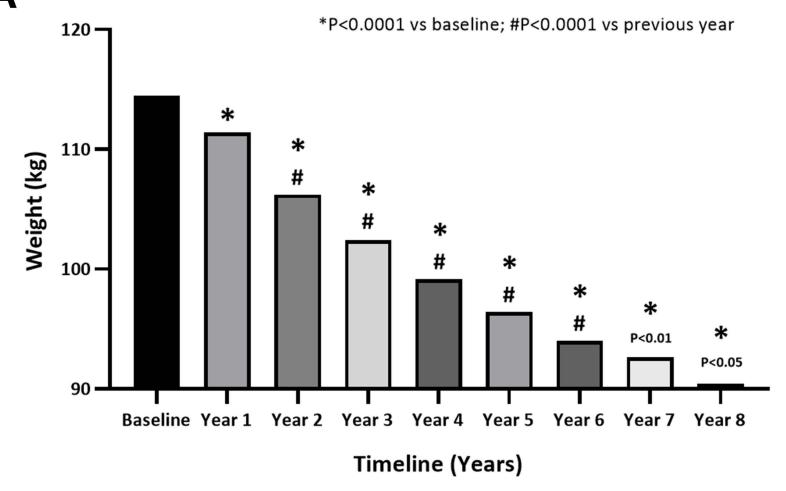

C

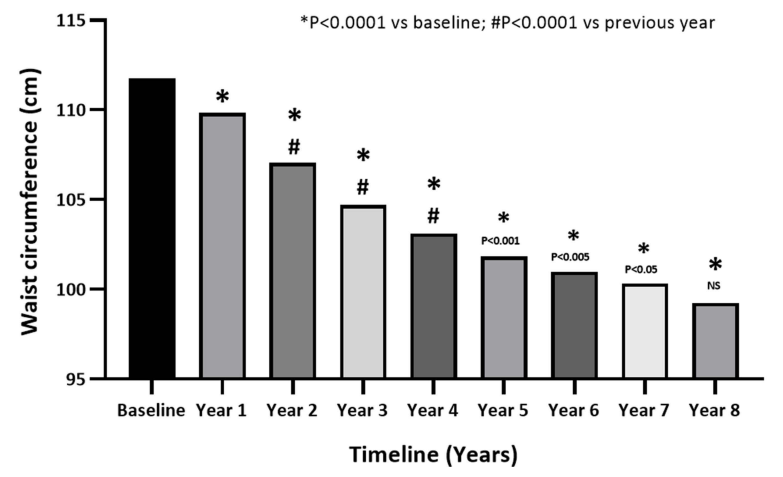

B

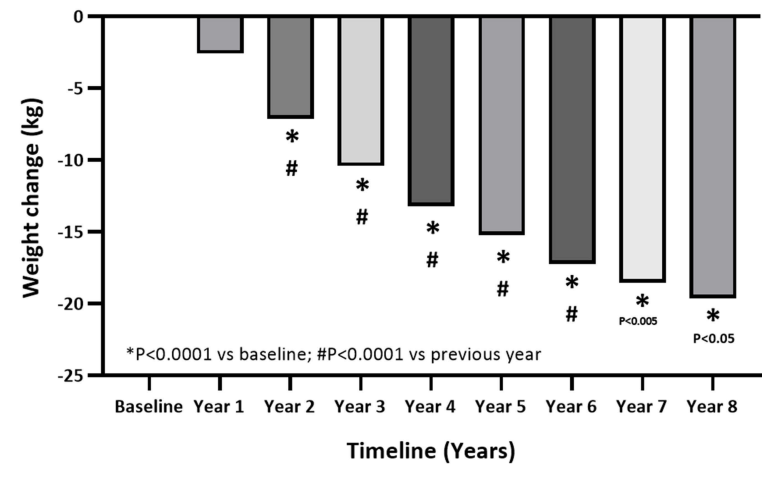

D

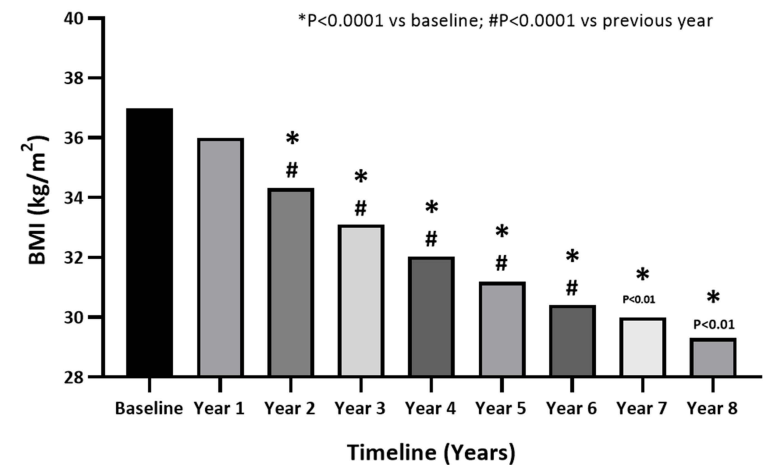

Figure 3 Anthropometric parameters in hypogonadal men with a history of cardiovascular disease receiving long-term testosterone therapy. Notes: (A) Body weight ( $\mathrm{kg}),(\mathbf{B})$ weight loss $(\%),(\mathbf{C})$ waist circumference $(\mathrm{cm})$, and (D) $\mathrm{BMI}\left(\mathrm{kg} / \mathrm{m}^{2}\right)$. Data are shown as mean. ${ }^{*}<0.000 \mathrm{I}$ vs baseline. $\# \mathrm{p}<0.000 \mathrm{I}$ vs previousyear.

Abbreviation: BMI, body mass index.

after 2 years, $6.6 \%$ after 3 years, $6.4 \%$ after 4 years, $6.2 \%$ after 5 years, $6.0 \%$ after 6 years, $5.9 \%$ after 7 years, and $5.7 \%$ after 8 years (Figure 4 ). $\mathrm{HbA}_{1 \mathrm{c}}$ had declined by an average of $2.0 \%(\mathrm{P}<0.0001)$ at the end of the follow-up period. The TGs:HDL-C ratio was used as a surrogate marker of insulin resistance and decreased from $5.4 \pm 2$ to $2.5 \pm 0.6(\mathrm{P}<0.0001)$.

\section{Effects on Lipid Profiles}

TC levels significantly declined following TTh after only 1 year $(\mathrm{P}<0.0001)$ and continued to gradually decline over the 8 -year follow-up period (Figure $5 \mathrm{~A}$ ). TC decreased from $7.8 \pm 0.9 \mathrm{mmol} / \mathrm{L}$ at baseline to $4.8 \pm 0.2 \mathrm{mmol} / \mathrm{L}$ after 8 years $(\mathrm{P}<0.0001)$. Similarly, following 8 years of TTh, LDL-C was reduced from $4.7 \pm 0.9$ to $3.0 \pm 0.7 \mathrm{mmol} / \mathrm{L}$ (Figure 5B), and TGs from $3.4 \pm 0.7$ to $2.1 \pm 0.1 \mathrm{mmol} / \mathrm{L}$ (Figure 5C) $(\mathrm{P}<0.0001)$. Furthermore, HDL increased from $1.6 \pm 0.5$ at baseline to $2 \pm 0.5 \mathrm{mmol} / \mathrm{L}$ following 8 years of TTh $(\mathrm{P}<0.0001)$ (Figure 6D). The TC:HDL ratio declined from $5.5 \pm 2.0$ at baseline to $2.6 \pm 0.7$ at 8 years $(\mathrm{P}<0.0001)$. Non-HDL cholesterol decreased from $6.2 \pm 0.8$ at baseline to $2.8 \pm 0.5 \mathrm{mmol} / \mathrm{L}$ at 8 years $)(\mathrm{P}<0.0001)$.

\section{Effects on SBP and DBP}

Long-term TTh in hypogonadal patients with a history of CVD resulted in marked and significant reduction in blood pressure. SBP decreased from $164 \pm 14$ at baseline to $133 \pm 9$ mmHg following 8 years of TTh, signifying a reduction of $33 \pm 1 \mathrm{mmHg}(\mathrm{P}<0.0001)$ (Figure 6A). The decrease in SBP was gradual but significant over the first 6 years compared to the previous year and gradually declined up to the end of the 8-year follow-up period. Similarly, 8 years of TTh reduced DBP by $24 \pm 1 \mathrm{mmHg}$ from $99 \pm 11 \mathrm{mmHg}$ at baseline to $77 \pm 5 \mathrm{mmHg}(\mathrm{P}<0.0001)$ (Figure $6 \mathrm{~B})$. Again, a significant decrease of DBP occurred over the first 6 years of treatment compared to the previous year and then remained low for the remainder of the 8-year follow-up period. 


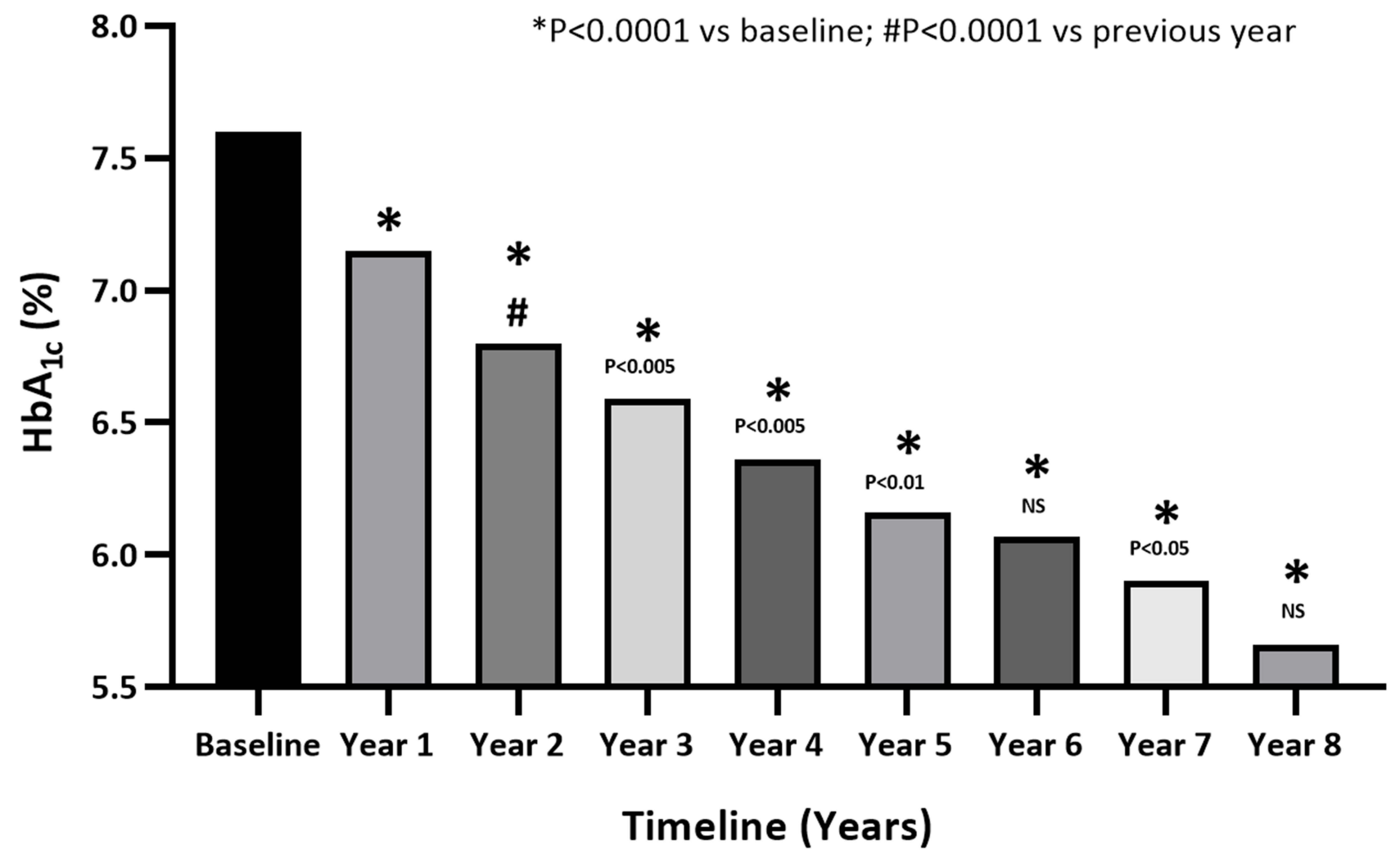

Figure $4 \mathrm{HbA}_{\mathrm{Ic}}(\%)$ in hypogonadal men with a history of cardiovascular disease receiving long-term testosterone therapy. Notes: Data are shown as mean. ${ }^{*} p<0.0001$ vs baseline. $\# p<0.0001$ vs previousyear. Abbreviation: $\mathrm{HbA}_{\mathrm{Ic}}$, glycated hemoglobin.

\section{Effects on Pulse Pressure}

Long-term TTh resulted significant reduction in pulse pressure from $65 \pm 6$ to $57 \pm 8$ in hypogonadal patients with a history of CVD. Pulse pressure was gradually and significantly reduced over the course of treatment compared to baseline with a mean change of $9 \pm 1$ at the end of the follow-up period. Pulse pressure finally dropped to within the normal range after 5 years of TTh (Figure 6C).

\section{Safety and Compliance}

There were no major adverse $\mathrm{CV}$ events recorded for any patient. No patient had a urological event (prostate cancer or voiding dysfunction). No patient missed a single TU injection. No patient dropped out.

\section{Discussion}

This observational registry assessing 77 hypogonadal men with a history of CVD on continuous TTh for up to 8 years demonstrated significant and progressive improvements in IIEF sexual function scores following long-term TU administration accompanied by decreased cardiovascular events compared to non-treated age and health status-matched controls. Furthermore, a gradual yet significant reduction in blood pressure following TTh was maintained over the entire 8-year treatment period. Importantly, $94 \%$ of the patients included in this study were on anti-hypertensives to control their blood pressure, although with limited success as baseline blood pressure was elevated prior to TTh. Pulse pressure, indicated as a surrogate marker for arterial stiffness, was also significantly reduced following TTh demonstrating further vascular improvements.

The benefits of TTh have been observed in men with congestive heart failure and cardiac ischemia/angina, including a reduction in carotid intima-media thickness (CIMT), a clinical surrogate marker of atherosclerosis. ${ }^{33}$ In the present study, we report that there were no $\mathrm{CV}$ deaths or major adverse $\mathrm{CV}$ events (MACE) recorded for any patient receiving TTh. The lack of MACE in patients with moderate/severe ED is particularly remarkable considering their worse baseline health status and higher mortality risk. Studies have previously shown that mortality in men with low testosterone levels was reduced following 
A

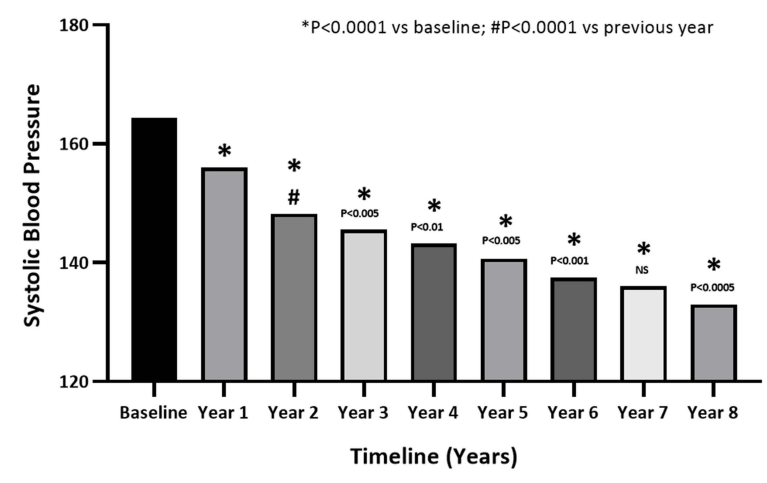

C

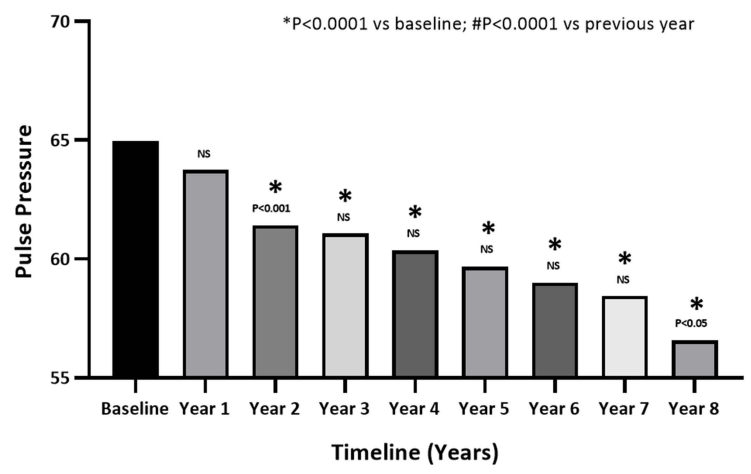

B

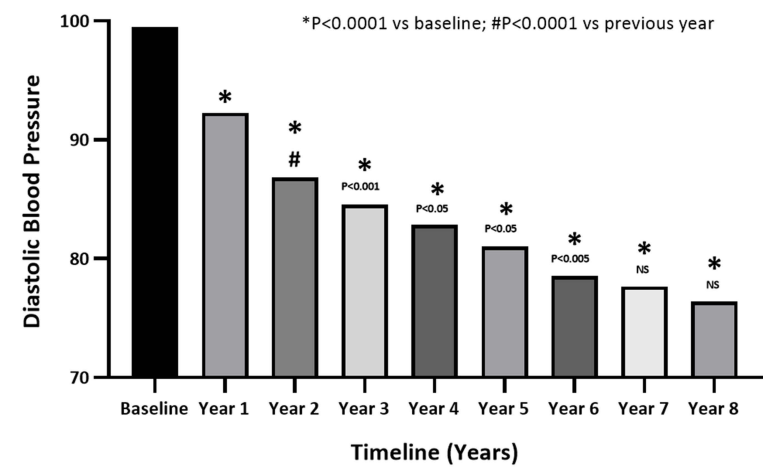

Figure 5 (A) Systolic and $(\mathbf{B})$ diastolic blood pressure $(\mathrm{mmHg})$ in hypogonadal men with a history of cardiovascular disease receiving long-term testosterone therapy. (C) Pulse pressure in hypogonadal men with a history of cardiovascular disease receiving long-term testosterone therapy.

Notes: (A) Systolic blood pressure and (B) diastolic blood pressure. Data are shown as mean. ${ }^{*} p<0.0001$ vs baseline. \#p $<0.000$ I vs previousyear. Abbreviation: NS, nonsignificant.

TTh. ${ }^{34,35}$ Shores et $\mathrm{al}^{34}$ observed that men receiving TTh had a lower mortality rate $(10.3 \%)$ compared with untreated hypogonadal men (20.7\%). Muraleedharan et $\mathrm{al}^{35}$ also observed that TTh in hypogonadal men with T2D reduced mortality to $8.4 \%$ compared with $19.2 \%$ in untreated men. Most importantly, following the 8-years of continuous TTh in the present study, we did not observe any increase in CVD risk in this subset of patients.

A negative correlation between testosterone and hypertension has been demonstrated in men. ${ }^{36}$ It is suggested that testosterone modulates arterial blood pressure via various mechanisms. ${ }^{37}$ Testosterone levels have reported being negatively associated with $\mathrm{SBP}^{36}$ In a study of 206 men from the Baltimore Longitudinal Study of Ageing, serum testosterone levels were an independent negative predictor for developing arterial stiffness. ${ }^{38}$ This association persisted after adjusting for risk factors such as age, pulse pressure, fasting plasma glucose, BMI and TC, suggesting that hypogonadism contributes to elevated blood pressure and TTh decreases blood pressure. ${ }^{39,40}$ In the current study, we report that TTh gradually, yet significantly decreases blood pressure, which was maintained over the 8-year follow-up period. Furthermore, pulse pressure (PP) is an indicator for arterial stiffness, which is related to endothelial dysfunction, and increased PP is related to increase risk of cardiovascular events, hence increase mortality. ${ }^{41,42}$ An association between ED and PP was revealed by the present study. In TTh group, a reduction in PP was noticed to be associated with a significant improvement in ED, whereas no improvement and a progressive deterioration was experienced in PP and ED in the other group. The present study therefore supports beneficial effects of TTh on vascular function reported in previous observational studies ${ }^{43}$ and placebocontrolled trials ${ }^{44}$ whereby a reduction in arterial stiffness was reported following TTh.

The most common cause of ED is an underlying vascular disease caused mainly by atherosclerosis within the 
A
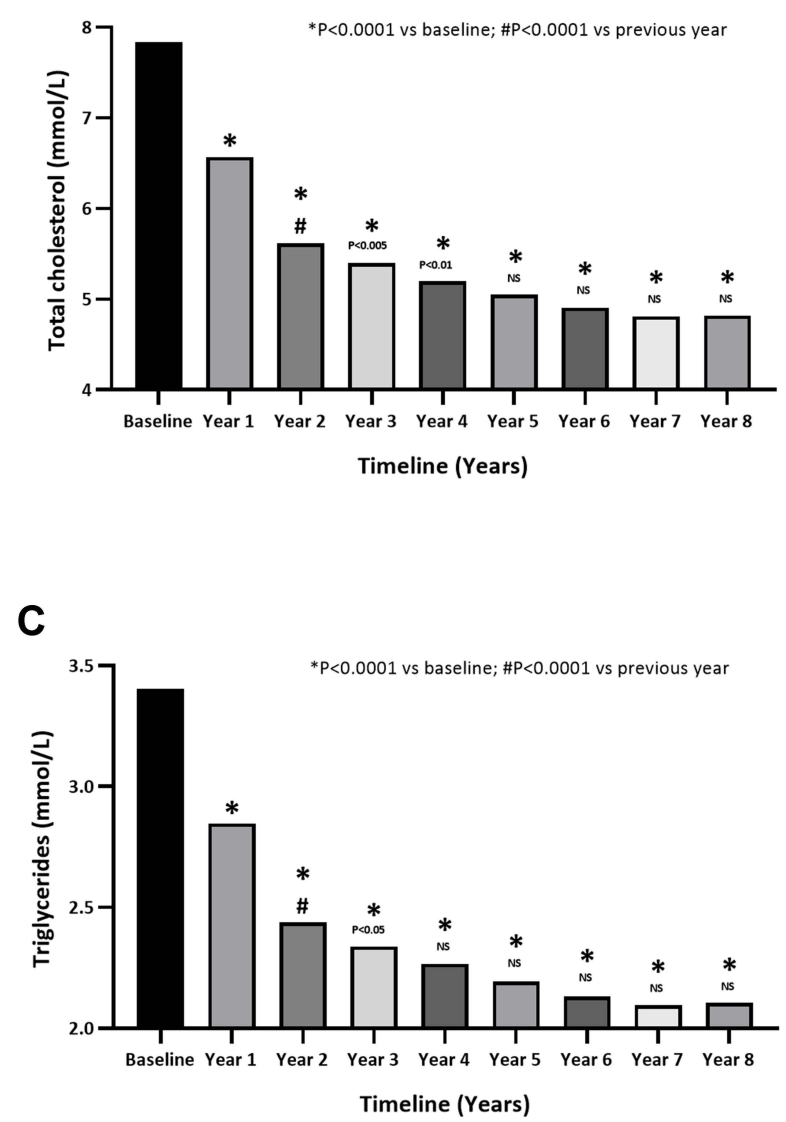

B

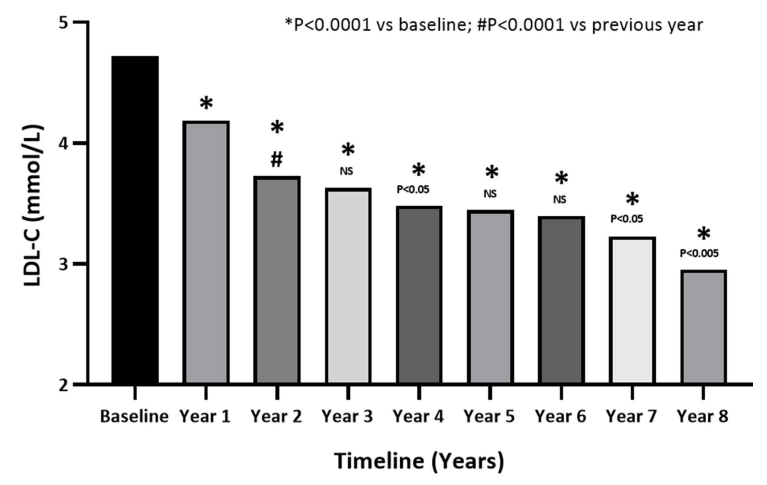

D

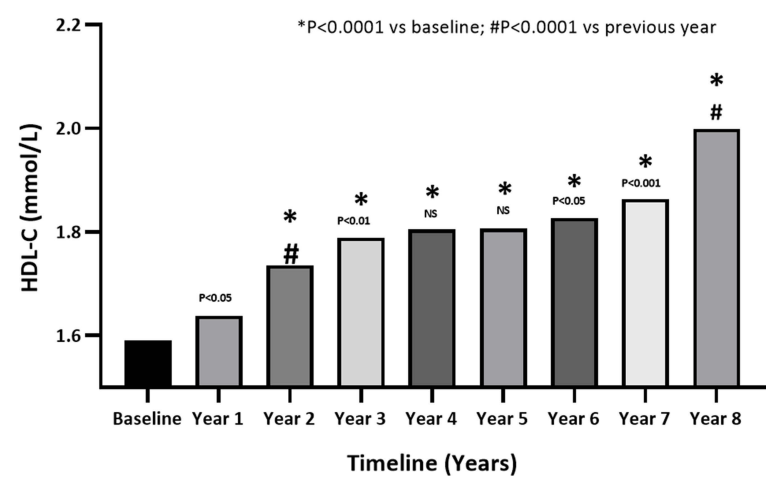

Figure 6 Serum lipids in hypogonadal men with a history of cardiovascular disease receiving long-term testosterone therapy (A) total cholesterol, (B) LDL-cholesterol, (C) triglycerides and (D) HDL-cholesterol. Note: Data are shown as mean. ${ }^{*} p<0.000$ I vs baseline. $\# p<0.000$ I vs previous year.

Abbreviations: LDL, low-density lipoprotein; HDL, high-density lipoprotein; NS, nonsignificant.

penile arteries, and the prevalence of ED is higher in patients with CVD. ${ }^{45}$ The severity of ED has been reported to directly correlate with the severity of the $\mathrm{CAD}^{14}$ and suggested as a potential indicator of silent CAD in men with uncomplicated T2D and relatively low CAD risk. ${ }^{9}$ Therefore, ED is considered a manifestation of a generalized vascular disease and has been suggested as an indicator for future cardiovascular events. The artery size hypothesis indicates that vascular disease may be comparative in arteries independent of location and vessel size yet the same level of endothelial dysfunction and atherosclerosis may lead to a more significant reduction of blood flow in erectile tissues compared with that in coronary arteries suggesting ED would precede CAD. ${ }^{11}$ Several studies show that ED manifests prior to CAD in approximately two-thirds of cases, ${ }^{12-14,46}$ with the time interval from ED to CAD symptoms being 2-3 years and ED to a cardiovascular event $3-5$ years. ${ }^{41}$ Due to the increased risk of $\mathrm{CAD}$ among men with functional hypogonadism and $\mathrm{ED}^{16}$ findings from our previous study ${ }^{42}$ and the present study, a role for routinely assessing ED to identify individuals at increased risk of CAD is supported. Indeed, hypogonadism is prevalent in patients with $\mathrm{ED}$, and low testosterone levels are reported in around $23-36 \%$ of the patients presenting with ED. ${ }^{15}$ Low testosterone levels are considered to be a predisposing risk for ED, and both ED and testosterone deficiency are both independently associated with increased risk of CAD. ${ }^{16}$ Therefore, identifying men at risk of CAD via diagnosis of ED and underlying.

Severe ED additionally functions as a prognostic indicator of cardiovascular risk comorbidities in men with functional hypogonadism. ${ }^{42}$ Indeed, our previous study suggested that the severity of ED within patients with functional hypogonadism correlated with comorbidities including increased waist circumference, hyperglycemia, hypertriglyceridemia, hyperlipidemia and a history of diabetes mellitus. ${ }^{47} \mathrm{ED}$ was found to be present in $33 \%$ of 
men with uncomplicated T2D and silent CAD, compared to the $5 \%$ in $\mathrm{T} 2 \mathrm{D}$ men without myocardial ischemia suggesting $\mathrm{ED}$ as an indicator of $\mathrm{CAD}$ in $\mathrm{T} 2 \mathrm{D}$ men. ${ }^{9}$ Furthermore, obesity and increased adiposity are common clinical features of functional hypogonadism frequently associated with ED. ${ }^{48}$ In the current study, TTh reduced weight, WC and mean BMI (which was within the obese range at baseline) in a gradual yet sustained manner. Additionally, despite being treated with statins to control their dyslipidemia, most patients exhibited elevated serum lipid profiles at baseline which were significantly improved (reduced TC, LDL-C, TGs and increased HDL-C) following long-term TTh. It worth to mention, that $25 \%$ of the patients did not undergone statin treatment, at which they are more susceptible to CAD. $\mathrm{HbA}_{1 \mathrm{c}}$ was also improved by TTh. The shared aetiology between metabolic dysfunction, vascular dysfunction and ED suggests that the improvements in ED and CVD following TTh in this study may be due to the overall improvement in metabolic parameters.

TTh to treat functional hypogonadism in the present investigation and other studies has resulted in improvement of components of MetS and T2D that are considered CVD risk factors, thus improving cardiometabolic function ${ }^{49}$ and reducing the risk of CVD. ${ }^{50,51}$ It is noted that continuous treatment with TTh is required to maintain the long-term benefits of testosterone. $^{52,53}$ These well-recognized benefits of TTh on metabolic parameters also extend to the improvement of erectile function and quality of life. ${ }^{51,54}$ Therefore, the IIEF-5 questionnaire may be regarded not only as a clinical indicator to screen for ED but also as a potential diagnostic tool to assess the global CAD risk profile of men with functional hypogonadism allowing early intervention with TTh to improve ED and CVD risk. However, in a cohort of men with erectile dysfunction it was suggested that hypogonadism-associated $\mathrm{CV}$ risk was dependent upon the characteristics of subjects, being more evident in normal weight than in obese patients. ${ }^{55}$ Conversely, in patients with a previous history of $\mathrm{CV}$ events, hypogonadism was associated with a reduced risk of new $\mathrm{CV}$ events, even after adjusting for confounders, whereas no relationship was observed in subjects free of previous CV events. ${ }^{56}$

This observational study is not without inherent limitations. As this was not a randomized placebo-controlled trial, it does not allow direct comparison of TTh versus non-treatment, limiting the scope of interpretation. However, we consider that the cardiovascular health benefits of TTh are time dependent, particularly when related to metabolic improvements, and therefore this real-world evidence study provides valuable data about the true clinical significance of TTh, which cannot be derived from RCTs due to their short-term nature. Longterm treatment is also more reflective of the therapeutic application of TTh for the responding patient, as we have previously demonstrated that treatment interruption can lead to regression of clinical benefits including parameters of cardiovascular health. ${ }^{52,57}$ Moreover, during long-term clinical trials, there are important ethical considerations of not treating hypogonadal men who presented at our clinic wishing to undergo TTh. Reported cardiovascular disease was the clinical outcome indicating vascular health, but assessing subclinical measures, such as carotid intima media thickness (CIMT) or vascular composition via CT scan, may give a more detailed analysis of disease progression, remission or regression.

\section{Conclusions}

The triad of aetiological disparities of low T, ED and CVD, correlate and interact to indicate an underlying negative health status in men and suggests that both ED and testosterone levels could have a predictive capacity for worse cardiovascular outcomes. This study indicates that ED may be an early predictor of CVD and low testosterone may be an early indicator of vascular dysfunction associated with ED and CVD, particularly in the presence of cardiometabolic risk factors. Due to the increased risk of CVD among men with functional hypogonadism, ${ }^{15}$ findings from our previous study ${ }^{42}$ and the present study, we support a role for routinely assessing ED to identify individuals at increased risk of CVD. Furthermore, a diagnosis of ED should prompt a clinical investigation of serum testosterone levels and consequently correlated CVD comorbidities, and TTh considered. Correcting testosterone levels in men via TTh may therefore confer a vascular benefit that leads to improvements in both CVD and ED. Indeed, the beneficial effect of long-term TTh on CVD-related major adverse events was clearly confirmed in the present study with no MI and no stroke reported in the TTh group. We demonstrate that long-term TTh for up to 8 years in men with functional hypogonadism and a history of CVD significantly improves erectile function and protects against CVD events. The present study highlights the importance for patients to remain on TTh consistently for an extended period of time compared to published randomized controlled studies in order to achieve the maximum benefits of TTh in clinical practice. Therefore, ED and testosterone status warrant thorough clinical assessment to identify "at-risk" males for the consideration of long-term TTh with the goal of correcting the 
biochemical hormonal defect to improve both sexual function and cardiovascular health.

\section{Acknowledgment}

Editorial support for this manuscript was provided by Astra-Health, www.astra-health.co.uk.

\section{Disclosure}

Prof. Dr Aksam Yassin reports grants from Bayer AG, during the conduct of the study; personal fees from honoraria, generally, outside the submitted work. Prof. Dr Farid Saad reports personal fees from Bayer AG, during the conduct of the study and outside the submitted work; and owns shares of Bayer AG, Berlin, Germany. The authors report no other potential conflicts of interest for this work.

\section{References}

1. Wu FC, Tajar A, Beynon JM, et al. Identification of late-onset hypogonadism in middle-aged and elderly men. $N$ Engl $J$ Med. 2010;363(2):123-135. doi:10.1056/NEJMoa0911101

2. Livingston M, Kalansooriya A, Hartland AJ, Ramachandran S, Heald A. Serum testosterone levels in male hypogonadism: why and when to check-A review. Int J Clin Pract. 2017;71(11). doi:10.1111/ijcp. 12995

3. Feldman HA, Longcope C, Derby CA, et al. Age trends in the level of serum testosterone and other hormones in middle-aged men: longitudinal results from the Massachusetts Male Aging Study. J Clin Endocrinol Metab. 2002;87(2):589-598. doi:10.1210/jcem.87.2.8201

4. Zarotsky V, Huang MY, Carman W, et al. Systematic literature review of the risk factors, comorbidities, and consequences of hypogonadism in men. Andrology. 2014;2(6):819-834. doi:10.1111/andr.274

5. Bosco C, Bosnyak Z, Malmberg A, Adolfsson J, Keating NL, Van Hemelrijck M. Quantifying observational evidence for risk of fatal and nonfatal cardiovascular disease following androgen deprivation therapy for prostate cancer: a meta-analysis. Eur Urol. 2015;68 (3):386-396. doi:10.1016/j.eururo.2014.11.039

6. Mazzola CR, Mulhall JP. Impact of androgen deprivation therapy on sexual function. Asian J Androl. 2012;14(2):198-203. doi:10.1038/ aja.2011.106

7. Gandaglia G, Briganti A, Jackson G, et al. A Systematic review of the association between erectile dysfunction and cardiovascular disease. Eur Urol. 2014;65(5):968-978. doi:10.1016/j.eururo.2013.08.023

8. Kapoor D, Clarke S, Channer KS, Jones TH. Erectile dysfunction is associated with low bioactive testosterone levels and visceral adiposity in men with type 2 diabetes. Int J Androl. 2007;30(6):500-507. doi:10.1111/j.1365-2605.2007.00744.x

9. Gazzaruso C, Giordanetti S, De Amici E, et al. Relationship between erectile dysfunction and silent myocardial ischemia in apparently uncomplicated type 2 diabetic patients. Circulation. 2004;110 (1):22-26. doi:10.1161/01.CIR.0000133278.81226.C9

10. Montorsi F, Briganti A, Salonia A, et al. Erectile Dysfunction prevalence, time of onset and association with risk factors in 300 consecutive patients with acute chest pain and angiographically documented coronary artery disease. Eur Urol. 2003;44(3):360-365. doi:10.1016/S0302-2838(03)00305-1

11. Montorsi P, Ravagnani PM, Galli S, et al. Association between erectile dysfunction and coronary artery disease: matching the right target with the right test in the right patient. Eur Urol. 2006;50 (4):721-731. doi:10.1016/j.eururo.2006.07.015
12. Hodges LD, Kirby M, Solanki J, O'Donnell J, Brodie DA. The temporal relationship between erectile dysfunction and cardiovascular disease. Int J Clin Pract. 2007;61(12):2019-2025. doi:10.1111/ j.1742-1241.2007.01629.x

13. Inman BA, St. Sauver JL, Jacobson DJ, et al. A population-based, longitudinal study of erectile dysfunction and future coronary artery disease. Mayo Clinic Proce. 2009;84(2):108-113. doi:10.4065/84. 2.108

14. Montorsi P, Ravagnani PM, Galli S, et al. Association between erectile dysfunction and coronary artery disease. Role of coronary clinical presentation and extent of coronary vessels involvement: the COBRA trial. Eur Heart J. 2006;27(22):2632-2639. doi:10.1093/ eurheartj/ehl142

15. Isidori AM, Buvat J, Corona G, et al. A critical analysis of the role of testosterone in erectile function: from pathophysiology to treatment-a systematic review. Eur Urol. 2014;65(1):99-112. doi:10.1016/j.eururo.2013.08.048

16. Jones TH. Testosterone deficiency: a risk factor for cardiovascular disease? Trends Endocrinol Metab. 2010;21(8):496-503. doi:10. 1016/j.tem.2010.03.002

17. Corona G, Monami M, Boddi V, et al. Low Testosterone is Associated with an Increased Risk of MACE Lethality in Subjects with Erectile Dysfunction. J Sex Med. 2010;7(4pt1):1557-1564. doi:10.1111/j.1743-6109.2009.01690.x

18. Feldman HA, Johannes CB, Derby CA, et al. Erectile dysfunction and coronary risk factors: prospective results from the Massachusetts male aging study. Prev Med. 2000;30(4):328-338. doi:10.1006/ pmed.2000.0643

19. Malkin CJ, Pugh PJ, Jones RD, Kapoor D, Channer KS, Jones TH. The effect of testosterone replacement on endogenous inflammatory cytokines and lipid profiles in hypogonadal men. J Clin Endocrinol Metab. 2004;89(7):3313-3318. doi:10.1210/jc.2003-031069

20. Malkin CJ, Pugh PJ, Morris PD, et al. Testosterone replacement in hypogonadal men with angina improves ischaemic threshold and quality of life. Heart. 2004;90(8):871-876. doi:10.1136/hrt.2003.021 121

21. Mathur A, Malkin C, Saeed B, Muthusamy R, Jones TH, Channer K. Long-term benefits of testosterone replacement therapy on angina threshold and atheroma in men. Eur $J$ Endocrinol. 2009;161 (3):443-449. doi:10.1530/EJE-09-0092

22. Kapoor D, Goodwin E, Channer KS, Jones TH. Testosterone replacement therapy improves insulin resistance, glycaemic control, visceral adiposity and hypercholesterolaemia in hypogonadal men with type 2 diabetes. Eur J Endocrinol. 2006;154(6):899-906. doi:10.1530/eje.1.02166

23. Heufelder AE, Saad F, Bunck MC, Gooren L. Fifty-two-week treatment with diet and exercise plus transdermal testosterone reverses the metabolic syndrome and improves glycemic control in men with newly diagnosed type 2 diabetes and subnormal plasma testosterone. J Androl. 2009;30(6):726-733. doi:10.2164/jandrol. 108.007005

24. Cornoldi A, Caminiti G, Marazzi G, et al. Effects of chronic testosterone administration on myocardial ischemia, lipid metabolism and insulin resistance in elderly male diabetic patients with coronary artery disease. Int $J$ Cardiol. 2010;142(1):50-55. doi:10.1016/j. ijcard.2008.12.107

25. Kalinchenko SY, Tishova YA, Mskhalaya GJ, Gooren LJ, Giltay EJ, Saad F. Effects of testosterone supplementation on markers of the metabolic syndrome and inflammation in hypogonadal men with the metabolic syndrome: the double-blinded placebo-controlled Moscow study. Clin Endocrinol (Oxf). 2010;73(5):602-612. doi:10.1111/ j.1365-2265.2010.03845.x

26. Sesti F, Pofi R, Minnetti M, Tenuta M, Gianfrilli D, Isidori AM. Lateonset hypogonadism: reductio ad absurdum of the cardiovascular risk-benefit of testosterone replacement therapy. Andrology. 2020;8 (6):1614-1627. doi:10.1111/andr.12876 
27. Hackett G, Cole N, Mulay A, Strange RC, Ramachandran S. Longterm testosterone therapy in type 2 diabetes is associated with decreasing waist circumference and improving erectile function. World J Mens Health. 2020;38(1):68-77. doi:10.5534/wjmh.180 052M

28. Permpongkosol S, Khupulsup K, Leelaphiwat S, Pavavattananusorn S, Thongpradit S, Petchthong T. Effects of 8-year treatment of long-acting testosterone undecanoate on metabolic parameters, urinary symptoms, bone mineral density, and sexual function in men with late-onset hypogonadism. J Sex Med. 2016;13(8):1199-1211. doi:10.1016/j. jsxm.2016.06.003

29. Giltay EJ, Tishova YA, Mskhalaya GJ, Gooren LJ, Saad F, Kalinchenko SY. Effects of testosterone supplementation on depressive symptoms and sexual dysfunction in hypogonadal men with the metabolic syndrome. J Sex Med. 2010;7(7):2572-2582. doi:10.1111/ j.1743-6109.2010.01859.x

30. Saad F, Caliber M, Doros G, Haider KS, Haider A. Long-term treatment with testosterone undecanoate injections in men with hypogonadism alleviates erectile dysfunction and reduces risk of major adverse cardiovascular events, prostate cancer, and mortality. Aging Male. 2020;23(1):81-92. doi:10.1080/13685538.2019.1575354

31. Cappelleri JC, Rosen RC, Smith MD, Mishra A, Osterloh IH. Diagnostic evaluation of the erectile function domain of the International Index of Erectile Function. Urology. 1999;54 (2):346-351. doi:10.1016/S0090-4295(99)00099-0

32. Rosen RC, Cappelleri JC, Gendrano N. The International Index of Erectile Function (IIEF): a state-of-the-science review. Int $J$ Impot Res. 2002;14(4):226-244. doi:10.1038/sj.ijir.3900857

33. English KM, Steeds RP, Jones TH, Diver MJ, Channer KS. Low-dose transdermal testosterone therapy improves angina threshold in men with chronic stable angina: a randomized, double-blind, placebo-controlled study. Circulation. 2000;102(16):1906-1911. doi:10.1161/01.CIR.102.16.1906

34. Shores MM, Matsumoto AM, Sloan KL, Kivlahan DR. Low serum testosterone and mortality in male veterans. Arch Intern Med. 2006;166(15):1660-1665. doi:10.1001/archinte.166.15.1660

35. Muraleedharan V, Marsh H, Kapoor D, Channer KS, Jones TH. Testosterone deficiency is associated with increased risk of mortality and testosterone replacement improves survival in men with type 2 diabetes. Eur j Endocrinol. 2013;169(6):725-733. doi:10.1530/EJE-13-0321

36. Svartberg J, von Mühlen D, Schirmer H, Barrett-Connor E, Sundfjord J, Jorde R. Association of endogenous testosterone with blood pressure and left ventricular mass in men. The Tromsø Study. Eur j Endocrinol. 2004;150(1):65-71. doi:10.1530/eje.0.1500065

37. Kelly DM, Jones TH. Testosterone: a vascular hormone in health and disease. J Endocrinol. 2013;217(3):R47-71. doi:10.1530/JOE-12-0582

38. Hougaku H, Fleg JL, Najjar SS, et al. Relationship between androgenic hormones and arterial stiffness, based on longitudinal hormone measurements. Am J Physiol Endocrinol Metab. 2006;290(2):E234242. doi:10.1152/ajpendo.00059.2005

39. Saad F, Haider A, Doros G, Traish A. Long-term treatment of hypogonadal men with testosterone produces substantial and sustained weight loss. Obesity. 2013;21(10):1975-1981. doi:10.1002/ oby. 20407

40. Saad F, Yassin A, Doros G, Haider A. Effects of long-term treatment with testosterone on weight and waist size in 411 hypogonadal men with obesity classes I-III: observational data from two registry studies. Int j Obesity. 2016;40(1):162-170. doi:10.1038/ijo.2015.139

41. Sai Ravi Shanker A, Phanikrishna B. Association between erectile dysfunction and coronary artery disease and its severity. Indian Heart J. 2013;65(2):180-186. doi:10.1016/j.ihj.2013.02.013

42. Almehmadi Y, Yassin DJ, Yassin AA. Erectile dysfunction is a prognostic indicator of comorbidities in men with late onset hypogonadism. Aging Male. 2015;18(3):186-194. doi:10.3109/ 13685538.2015.1046044
43. Traish AM, Haider A, Haider KS, Doros G, Saad F. Long-Term testosterone therapy improves cardiometabolic function and reduces risk of cardiovascular disease in men with hypogonadism: a real-life observational registry study setting comparing treated and untreated (control) groups. J Cardiovasc Pharmacol Ther. 2017;22(5):414-433.

44. Hoyos CM, Yee BJ, Phillips CL, Machan EA, Grunstein RR, Liu PY. Body compositional and cardiometabolic effects of testosterone therapy in obese men with severe obstructive sleep apnoea: a randomised placebo-controlled trial. Eur j Endocrinol. 2012;167(4):531-541. doi:10.1530/EJE-12-0525

45. Solomon H, Man JW, Jackson G. Erectile dysfunction and the cardiovascular patient: endothelial dysfunction is the common denominator. Heart. 2003;89(3):251. doi:10.1136/heart. 89.3.251

46. Ponholzer A, Temml C, Obermayr R, Wehrberger C, Madersbacher S. Is Erectile Dysfunction an Indicator for Increased Risk of Coronary Heart Disease and Stroke? Eur Urol. 2005;48(3):512-518. doi:10.1016/j.eururo.2005.05.014

47. Yassin AA, Nettleship JE, Almehmadi Y, Yassin D-J, El Douaihy Y, Saad F. Is there a relationship between the severity of erectile dysfunction and the comorbidity profile in men with late onset hypogonadism? Arab J Urol. 2015;13(3):162-168. doi:10.1016/j. aju.2015.06.003

48. Saad F, Gooren LJ, Haider A, Yassin A. A dose-response study of testosterone on sexual dysfunction and features of the metabolic syndrome using testosterone gel and parenteral testosterone undecanoate. J Androl. 2008;29(1):102-105. doi:10.2164/ jandrol.107.002774

49. Jones TH, Saad F. The effects of testosterone on risk factors for, and the mediators of, the atherosclerotic process. Atherosclerosis. 2009;207(2):318-327. doi:10.1016/j.atherosclerosis.2009.04.016

50. Jones TH. Testosterone replacement therapy. $\mathrm{Br} j$ Hospital Med. 2007;68(10):547-553. doi:10.12968/hmed.2007.68.10.27326

51. Corona G, Maseroli E, Rastrelli G, et al. Cardiovascular risk associated with testosterone-boosting medications: a systematic review and meta-analysis. Expert Opin Drug Saf. 2014;13(10):1327-1351. doi:10.1517/14740338.2014.950653

52. Yassin A, Nettleship JE, Talib RA, Almehmadi Y, Doros G. Effects of testosterone replacement therapy withdrawal and re-treatment in hypogonadal elderly men upon obesity, voiding function and prostate safety parameters. Aging Male. 2016;19(1):64-69. doi:10.3109/ 13685538.2015.1126573

53. Yassin A, Almehmadi Y, Saad F, Doros G, Gooren L. Effects of intermission and resumption of long-term testosterone replacement therapy on body weight and metabolic parameters in hypogonadal in middle-aged and elderly men. Clin Endocrinol (Oxf). 2016;84 (1):107-114. doi:10.1111/cen.12936

54. Hackett G, Cole N, Bhartia M, Kennedy D, Raju J, Wilkinson P. Testosterone replacement therapy with long-acting testosterone undecanoate improves sexual function and quality-of-life parameters vs. placebo in a population of men with type 2 diabetes. J Sex Med. 2013;10(6):1612-1627. doi:10.1111/jsm.12146

55. Corona G, Rastrelli G, Monami M, et al. Body Mass index regulates hypogonadism-associated cv risk: results from a cohort of subjects with erectile dysfunction. $J$ Sex Med. 2011;8(7):2098-2105. doi:10.1111/j.1743-6109.2011.02292.x

56. Corona G, Rastrelli G, Maseroli E, et al. Low testosterone syndrome protects subjects with high cardiovascular risk burden from major adverse cardiovascular events. Andrology. 2014;2(5):741-747. doi:10.1111/j.2047-2927.2014.00241.x

57. Saad F, Yassin A. Effects of interrupting and resuming long-term testosterone replacement therapy (TRT) with testosterone undecanoate injections (TU) on erectile dysfunction (ED) and anthropometric parameters in hypogonadal men in an observational registry study. J Sexual Med. 2015;12:402. 


\section{Publish your work in this journal}

Vascular Health and Risk Management is an international, peerreviewed journal of therapeutics and risk management, focusing on concise rapid reporting of clinical studies on the processes involved in the maintenance of vascular health; the monitoring, prevention and treatment of vascular disease and its sequelae; and the involvement of metabolic disorders, particularly diabetes. This journal is indexed on PubMed Central and MedLine. The manuscript management system is completely online and includes a very quick and fair peerreview system, which is all easy to use. Visit http://www.dovepress. com/testimonials.php to read real quotes from published authors.

Submit your manuscript here: https://www.dovepress.com/vascular-health-and-risk-management-journal 